\title{
Pleomorphic adenoma gene like-2 induces epithelial-mesenchymal transition via Wnt/及-catenin signaling pathway in human colorectal adenocarcinoma
}

\author{
YONG-PENG WANG ${ }^{1,2}$, PENG-TAO GUO $^{3}$, ZHI ZHU $^{3}$, HAO ZHANG $^{1,2}$, \\ YAN XU ${ }^{3}$, YU-ZE CHEN ${ }^{1,2}$, FANG LIU ${ }^{1,2}$ and SI-PING MA ${ }^{1,2}$ \\ ${ }^{1}$ Department of Colorectal Surgery, Cancer Hospital of China Medical University, Shenyang, Liaoning; \\ ${ }^{2}$ Department of Colorectal Surgery, Liaoning Cancer Hospital and Institute, Shenyang, Liaoning; \\ ${ }^{3}$ Department of Surgical Oncology, First Affiliated Hospital of China Medical University, Shenyang, Liaoning, P.R. China
}

Received July 24, 2016; Accepted February 15, 2017

DOI: $10.3892 /$ or.2017.5485

\begin{abstract}
Epithelial-mesenchymal transition (EMT) is a critical step in the acquisition of metastatic and invasive power for tumor cells. Colorectal adenocarcinoma (CRC) is a common cancer where metastasis is directly linked to patient survival. Recent studies show that pleomorphic adenoma gene like-2 (PLAGL2) could induce tumor EMT and is an independent predictive factor associated with poor prognosis in cancer. In the present study, we confirmed the role of PLAGL2 in the prognosis of CRC patients and provide molecular evidence of PLAGL2 promoted EMT in CRC cell line SW480. We found that PLAGL2 expression was upregulated in the paraffin-embedded CRC tissues compared to borderline or benign tissues. Experimental EMT induced by PLAGL2 plasmid transfection proved PLAGL2 protein overexpression could enhance the cell scratch wound-healing and Transwell ability and significantly upregulated mesenchymal marker proteins, $\mathrm{N}$-cadherin and vimentin and concurrently downregulated epithelial marker of E-cadherin. Subsequently, through western blot assay, we found that PLAGL2 could activate the $W n t$-signaling component $\beta$-catenin in the nuclei. More CRC cell metastasis to the lungs was observed when the PLAGL2 overexpressing SW480 cells were injected into the tail vein of rats, compared with the cell control and PLAGL2 silence group. Our findings indicated that PLAGL2 might be a very upstream key molecule regulating EMT involved in $W n t / \beta$-catenin signaling pathway.
\end{abstract}

Correspondence to: Dr Si-Ping Ma, Department of Colorectal Surgery, Liaoning Cancer Hospital and Institute, No. 44 Xiaoheyan Street, Dadong, Shenyang, Liaoning 110042, P.R. China E-mail: si_pingma@163.com

Key words: epithelial-mesenchymal transition, colorectal adenocarcinoma, E-cadherin, N-cadherin, pleomorphic adenoma gene like-2, vimentin, Wnt/ $\beta$-catenin

\section{Introduction}

Colorectal cancer is one of the most frequently diagnosed cancer and ranks second in cancer related deaths worldwide $(1,2)$. Although mortality from colorectal cancer has been progressively declining over the past two decades, a large number of colorectal cancer patients present with regional or distal metastatic cancer (3). Among multiplex mechanisms, epithelial-mesenchymal transition (EMT) is the most important one to bestow metastatic potential to epithelial cancer cells enabling them to invade, migrate and subsequently disseminate to distant metastases $(4,5)$. EMT is a reversible multi-step process by virtue of which epithelial cells lose their apical polarity and adhesion with other cells and/or extracellular matrix (ECM) and acquire mesenchymal traits of plasticity, mobility and stem cell-like properties (6). EMT is an essential physiological and patho-physiological process which is active during numerous embryogenesis processes and wound healing (7); but unfortunately, EMT can also occur during cancer progression when tumor cells exploit this mechanism to gain invasive and metastatic potential (8). EMT is the dominant program in human colon cancer, because robust EMT biology is highly prognostic for colon cancer recurrence (9). The EMT process also can induce autocrine signaling involving VEGF and Flt-1 that enable invasive cells to become 'self-sufficient' for survival (10). Induction of EMT in transformed colorectal epithelial cells could induce cells with circulating tumor cell (CTC) properties (10) suggesting that EMT may play a critical role in progression and metastases of colorectal cancer.

EMT changes will cause some signaling pathways activation, thus, some special biomarkers could be detected in the procedure. Aberrant activation of the Wnt signaling pathway is thought to be the initiation of tumor cell EMT (11-13). Binding of Wnt proteins to their trans-membrane cell receptors can activate the downstream pathway known as the $W n t / \beta$-catenin pathway. The $\beta$-catenin protein is the pivotal molecule in this pathway, and is stabilized by the ligand molecule T-cell factor/ lymphoid enhancer-binding factor-1 (TCF/LEF-1) to form a functional transcription factor that mediates the activation 
of target genes involved in tumor generation, invasion and metastasis $(12,14)$. The activation of $W n t / \beta$-catenin pathway can increase the expression of mesenchymal cell marker vimentin, which is also considered to be an EMT marker (15). Vimentin is a type III intermediate filament protein that is normally expressed in mesenchymal cells and in migratory epithelial cells, such as during embryogenesis and wound healing (16). Vimentin is the cytoskeletal component playing a significant role in anchoring the position of the organelles, such as nucleus, endoplasmic reticulum and mitochondria, in the cytosol for maintaining cell integrity (17). Vimentin is also overexpressed in some malignant diseases (18-20). Vimentin gene is methylated in colorectal cancer and has been established as a biomarker of colon cancer (21). Because the promoter has been identified to be a target of the $\beta$-catenin-TCF/LEF-1 transcription factor, vimentin now is regarded as an EMT marker (16).

When EMT occurs, tumors upregulate mesenchymal protein marker $\mathrm{N}$-cadherin and the concurrent loss of the epithelial protein marker E-cadherin $(22,23)$. E-cadherin downregulated expression is frequently observed in many different types of cancer (24-27); while $\mathrm{N}$-cadherin in various cancer cell lines enhances their invasion and metastasis even in the presence of E-cadherin (28). Interaction between $\mathrm{N}$-cadherin the fibroblast growth factor receptor 1 (FGFR1) leads to activation of the MAPK/ERK pathway which might promote tumor cell survival and get into the circulation $(29,30)$. E-cadherin, also called CD324, encoded by the CDH1 gene, is a major calcium-dependent glycoprotein adhesion molecule mediating cell-cell adhesion in epithelial cells (31-33). E-cadherin functions as a tumor suppressor contributing to make tumor cells lose or decrease function of proliferation, invasion and/or metastasis (33).

Pleomorphic adenoma gene-like 2 (PLAGL2) is a class zinc finger protein derived from PLAGL gene family and with the structures of the seven $\mathrm{C} 2 \mathrm{H} 2$ zinc finger domain on the N-terminal (34). Human PLAGL2 gene expression is rich in fetal period (34). The relationship between PLAGL2 and malignant tumor was first studied in patients with acute myeloid leukemia and lung cancer $(35,36)$. Zheng et al $(37)$ reported enhanced expression of PLAGL2 in neural stem cells (NSC) and glioma initiating cells (GIC) in cell lines and found that PLAGL2 gene overexpression strongly inhibits cell differentiation as well as enhance their ability of self-renew. The mechanism may be related to the regulation on the Wnt signaling pathway to prevent cell differentiation (37). Overexpression of PLAGL2 resulted in the combination of ligand and receptor in Wnt signaling pathway and subsequently Axin/APC/GSK3- $\beta$ diamorph disrupted, thus, promoting the stability of $\beta$-catenin activation and its transfer into the nucleus. This functionally contributes to PLAGL2 mediated NSC stop of differentiation and maintain self-renewal ability (37). In addition, recent research results show that PLAGL2 can regulate the actin cytoskeleton structure and cell migration, therefore, plays an important role in cell transformation and apoptosis (38). In the two ovarian cancer cell lines, ES-2 and HEY, knockout of PLAGL2 results in RhoA activation and Rac1 inactivation; subsequently, RhoA-ROCK (Rho-associated coil-containing protein kinase) pathway activation considerably increases invasive properties of the cells and significantly promote the organization of actin stress fibers and focal adhesions in a RhoA-dependent manner; to the contrary, exogenous overexpression of PLAGL2 in the breast cancer MDA-MB-231 cells, results in RhoA inactivation and Rac1 activation (39).

A previous study revealed that PLAGL2 is a transcription factor that correlated with the development, progression and prognosis of gastrointestinal cancer (40). In the study, 225 cases of colorectal cancer specimens and 66 cases of carcinoma adjacent non-tumor tissue were detected and the immunohistochemical analysis reveal that PLAGL2 is expressed significantly higher in colorectal cancer tissues and closely related to the depth of the tumor invasion (40).

In the present study, based on the theories and research findings above, the PLAGL2 was selected to explore its expression occurring in colorectal cancer oncogenesis, development and transfer. Furthermore, the mechanism of PLAGL2 action at the cellular level was investigated to clarify the mechanism of influence of the PLAGL2 on the occurrence and development of colorectal cancer and to provide a new theoretical basis for the treatment of colorectal cancer.

\section{Materials and methods}

Tissue specimens and data collection. All 44 CRC cases from January 1, 2012 to December 31, 2014 were collected in this study and they were included according to the following criteria: i) First-time diagnosed CRC patients without any chemo, radio, bio-immune or hormone therapy; and ii) without other tumors. The age of the patients ranged from 51 to 87 years (mean, 60.6 years). Written informed consent was obtained from each participant before sample and data collection. The malignant and borderline tissues were extracted from the surgical pathology archives in the Liaoning Cancer Hospital and Institute. Follow-up data were conducted using hospital medical records.

Immunohistochemistry (IHC) and assessment. The protein expression of PLAGL2 in the tissue samples were detected using immunohistochemistry. In brief, tissue sections were deparaffinized with xylene and gradually rehydrated in descending grades of ethanol. Antigen was retrieved by pressure cooking in $10 \mathrm{mM}$ sodium citrate buffer ( $\mathrm{pH}$ 6.0) at $20 \mathrm{psi}, 121^{\circ} \mathrm{C}$ for $30 \mathrm{sec}$ and $90^{\circ} \mathrm{C}$ for $10 \mathrm{sec}$. Endogenous peroxidase activities were blocked with endogenous peroxidase blocking agent (Dako, Kyoto, Japan) for $10 \mathrm{~min}$ followed by washing with $0.05 \%$ Tween-20/phosphate-buffered saline (PBST). The sections were then incubated with 1:40 dilution of rabbit polyclonal primary antibody against PLAGL2 (ab121239; Abcam, Cambridge, UK) at $37^{\circ} \mathrm{C}$ for $35 \mathrm{~min}$. Sections were treated with secondary antibodies at $37^{\circ} \mathrm{C}$ for 30 min by Dako ChemMate Detection kit peroxidase/DAB+, rabbit/ mouse kit (Dako). Finally, tissue sections were counterstained using haematoxylin. Primary malignant tissue grade 4 was applied as positive control of PLAGL2; negative control was performed using the normal tissue and the same condition.

The strength of cell positive-staining was estimated in a semi-quantitative method. The score of the staining intensity was classified as colorless (0), buff (1), brownish yellow (2), and dark brown (3) and the score of the positive cell percentage 
was classified as no positive cells (0), $15 \%$ positive cells or less (1), $16-50 \%$ positive cells (2), $51-75 \%$ positive cells (3), and $>75 \%$ positive cells (4). The staining index was calculated by multiplying the staining intensity score to the positive cell percentage score. Finally, we applied the mean optical density (MOD) to evaluate the staining intensity of each slide for the consistencies in IHC staining intensities. The MOD of each slices were determined by randomly selecting 6 representative fields, which were used to represent the whole tissue concentration of the stain or proportion of positive pixels.

Construction of the pcDNA3.1-PLAGL2. The human cDNA template was preserved in our laboratory. The PCR condition was $95^{\circ} \mathrm{C}$ for $5 \mathrm{~min}$ followed by 30 cycles at $95^{\circ} \mathrm{C}$ for $30 \mathrm{sec}, 55 \mathrm{~V}$ for $30 \mathrm{sec}$ and $72^{\circ} \mathrm{C}$ for $1 \mathrm{~min}$ plus a final extension period at $72^{\circ} \mathrm{C}$ for $5 \mathrm{~min}$. The PCR products were confirmed by $1.0 \%$ agarose gel electrophoresis and ligated into pUM-T simple vector (Beijing Bioteke Biotechnology, Co., Ltd., Beijing, China). Positive clones were sequenced by ABI 3730xl sequencer (Applied Biosystems, Carlsbad, CA, USA). Subsequently, the plasmid of T-PLAGL2 and pcDNA3.1 (Beijing Bioteke Biotechnology) were extracted using a plasmid preparation kit (Beijing Bioteke Biotechnology) and the nucleotides digested with BamHI (Fermentas, Vilnius, Lithuania) and EcoRI (Fermentas) enzymes. The gel purified segments were ligated using T4 DNA ligase (Fermentas). The constructed vector was transformed into $E$. coli and positive colons labeled pcDNA3.1- PLAGL2 were identified by colony PCR.

Cell culture and the pcDNA3.1-PLAGL2 transfection. SW480, human colon adenocarcinoma cell line, was obtained from the Cell Bank of Shanghai Institutes for Biological Sciences, Chinese Academy of Science (SIBS; Shanghai, China) and cultured in Dulbecco's modified Eagle's medium(DMEM) supplemented with $10 \%$ fetal bovine serum (FBS) and kept in a humidified incubator (Heracell 150i; Thermo Fisher Scientific, Langenselbold, Germany) at $37^{\circ} \mathrm{C}, 5 \% \mathrm{CO}_{2}$. After reaching 90-95\% confluency, SW480 cells were transfected with the vector pcDNA3.1- PLAGL2 using Lipofectamine ${ }^{\mathrm{TM}}$ 2000 (Invitrogen, Carlsbad, CA, USA) following the manufacturer's instructions. Forty-eight hours later, G418, $200 \mathrm{mg} / \mathrm{l}$ (Invitrogen) was added to the culture medium for cell selection. Single or mixed clonal populations of stably transfected cells were grown under G418 selection for 1-2 weeks and followed by routine DMEM culture for 2 weeks. The expression level of PLAGL2 in G418-resistant clones was thereafter evaluated by real-time reverse transcription-polymerase chain reaction (RT-PCR) and western blot analysis.

Construction of PLAGL2-silence vector and its identification and transfection. The human PLAGL2 gene nucleotide sequence NM-002657.2 was found in GeneBank, then PLAGL2 siRNA target sequence: AAGTGGGCTGGAAAC TAGTTC was selected applying siRNA Target Finder (Ambion ${ }^{\circledR}$; Thermo Fisher Scientific, Austin, TX, USA) and the gene alignment analysis was performed using NCBI's BLAST to confirm the specificity of the gene silence. According to the selected siRNA target sequence, synthetic two single stranded template DNA, 5'-AAAGCAGGAGGAG
GAAGTGG-3' and 5'-CAGCTATATGGTCTCTGCTC-3', were designed and synthetized. Positive sense oligonucleotide $3 \mu \mathrm{l}$ and antisense oligonucleotide $3 \mu \mathrm{l}$ were mixed and incubated at $90^{\circ} \mathrm{C}$ for $3 \mathrm{~min}$ and then slowly cooled to $37^{\circ} \mathrm{C}$ for $60 \mathrm{~min}$. The annealing fragment was inserted into pSilencer 2.0-U6 vector between the enzyme cut sites of BamHI and HindIII. The plasmid was transformed into XL1-Blue TSS ultra-competent cells. Six to eight clones were selected for plasmid extraction and colony PCR. Finally, siRNA insert fragment was identified by a $2 \%$ agarose gel electrophoresis and sequencing.

SW480 cells $\sim 2 \times 10^{4}$ each well was cultured in 24-well plate, $37^{\circ} \mathrm{C}, 5 \% \mathrm{CO}_{2}$, overnight. After the cells grew to $90-95 \%$ confluent monolayer, the recombinant plasmid and liposome FuGENE 6 to 1:2 mixing ratio were transfected into the cells. Twenty-four hours later, the cells were diluted with 1:10 and then cultured in the fresh medium. After $48 \mathrm{~h}$, the cells were replaced with medium with G418 $400 \mathrm{mg} / \mathrm{l}$ for the selection of culture medium. The resistant clones were obtained approximately 3 weeks later, and the cells were cultured with maintenance medium containing G418 of $200 \mathrm{mg} / \mathrm{l}$ culture. In the present study, the siPLAGL2 expression in SW480 cell line was selected as the experimental group, and the wild-type SW480 cell line was used as the control group.

Quantitative polymerase chain reaction $(q-P C R)$. All operations were performed using RNase free instruments treated with DEPC. Total RNA of the tissues or cells were extracted using RNeasy Mini kit (Qiagen, Hilden, Germany) and cDNA was synthesized using reverse transcription PCR kit, SuperScript $^{\mathrm{TM}}$ III First-Strand Synthesis system for RT-PCR (Life Technologies, Grand Island, NY, USA), according to the manufacturer's instruction. PLAGL2 gene expression at the mRNA level was tested by quantitative polymerase chain reaction (q-PCR) using Exicycler ${ }^{\mathrm{TM}} 96$ Real-Time Quantitative Thermal Block from Bioneer (Shanghai, China). All samples were run in triplicate in a total volume of $20 \mu \mathrm{l}$, which contains cDNA templet $1 \mu \mathrm{l}, 10 \mu \mathrm{M}$ forward primers $0.5 \mu \mathrm{l}, 10 \mu \mathrm{M}$ reversed primer $0.5 \mu \mathrm{l}$, SYBR-Green Master Mix $10 \mu \mathrm{l}$ and nuclease-free water. Amplification was carried out with polymerase activation at $95^{\circ} \mathrm{C}$ for $10 \mathrm{~min}$ followed by 40 cycles at $95^{\circ} \mathrm{C} 10 \mathrm{sec}, 60^{\circ} \mathrm{C} 20 \mathrm{sec}$ and $72^{\circ} \mathrm{C} 30 \mathrm{sec}$. Human $\beta$-actin was used as the reference gene. The relative expression analysis was performed using the $2^{-\Delta \Delta \mathrm{Ct}}$ relative quantification (RQ) method by comparing $\mathrm{Ct}$ values of PLAGL2 mRNA expression relative to the reference gene.

Scratch wound-healing and Transwell assays. Cell motility was evaluated using scratch wound-healing and Transwell assays. For the scratch wound-healing assay, SW480 cells $\left(2.5 \times 10^{5} / \mathrm{ml}\right)$ were seeded in 6 -well plates and grown to $80-90 \%$ confluence. After aspirating the growth medium, cell monolayers in each group were scratched with a sterile pipette tip to generate a denuded zone. Subsequently, the well plate was washed with PBS to remove the cellular debris and the cells left were cultured in the DMEM medium again. The images were taken using a Olympus microscope (CH-BI45-T; Olympus, Tokyo, Japan) at 0 and $24 \mathrm{~h}$ of incubation. The widths of the wound were counted in 10 randomly screened fields and the same procedure was repeated three times. 
For the Transwell assay, Matrigel (BD Biosciences, San Jose, CA, USA)-coated Transwells ( $8-\mu \mathrm{m}$ pore PET membrane; Millipore, Billerica, MA, USA) was applied. Briefly, $2 \times 10^{5}$ cells were seeded into the top chamber of a Corning chamber (polycarbonate filter with $8-\mu \mathrm{m}$ pore size inserts; Corning Incorporated, San Diego, CA, USA) in serum-free medium containing $0.3 \%$ BSA. Medium containing $10 \%$ serum was placed in the lower chamber. After $24 \mathrm{~h}$, cells that migrated to the underside of the membrane were detected using a $0.1 \%$ crystal violet solution the assay was repeated three times with three replicates each. Cells that migrated to the underside of the membrane were quantified using light microscopy (Nikon Eclipse TE2000-S; Nikon, Tokyo, Japan). Crystal violet was dissolved using a $33 \%$ acetic acid, and the OD ratio at $570 \mathrm{~nm}$ was determined using a microplate reader. The results are representative of three independent experiments.

Fractionation of cytoplasmic and nuclear proteins. The nuclear plasma protein isolation and extraction kit and the protease inhibitor cocktail were purchased from Fermentas, Thermo Fisher Scientific. Briefly, Lamin B1 was used as loading control for nuclear proteins western blot analysis. After digestion of the cells, the samples were centrifuged $250 \mathrm{x}$ g at $4^{\circ} \mathrm{C}$ for $5 \mathrm{~min}$ and then the supernatant was discarded, then 10 volumes of cell lysis buffer with added protease inhibitor and DTT was added and the mixture was shaken for $10 \mathrm{sec}$ and then placed on ice for $10 \mathrm{~min}$. The samples were centrifuged $250 \mathrm{x} \mathrm{g}$ at $4^{\circ} \mathrm{C}$ for $7 \mathrm{~min}$. The supernatant was collected carefully into the new EP tube and the remaining precipitate was placed on ice. The supernatant in the new EP tube was centrifuged $20,000 \mathrm{xg}$ at $4^{\circ} \mathrm{C}$ for $15 \mathrm{~min}$ and the supernatant, which contained the plasma proteins, was transferred into the new EP tube and stored at $-70^{\circ} \mathrm{C}$.

To the previous remaining precipitate was added $500 \mu \mathrm{l}$ nuclei washing buffer containing protease inhibitor and DTT and then shaken gently and placed on ice for $2 \mathrm{~min}$. The samples were centrifuged $500 \mathrm{xg}$ at $4^{\circ} \mathrm{C}$ for $7 \mathrm{~min}$ and the supernatant was removed carefully. Nuclei storage buffer, $150 \mu 1$, containing protease inhibitor and DTT was added and mixed 5-10 times. Nuclei lysis reagent 1/10 volume was added and shaken $900-1,200 \mathrm{rpm}$ at $4^{\circ} \mathrm{C}$ for $15 \mathrm{~min}$. The samples were centrifuged $20,000 \mathrm{x}$ g at $4^{\circ} \mathrm{C}$ for $15 \mathrm{~min}$ and transferred to the supernatant, which contained the nuclear proteins, into a new EP tube and stored at $-70^{\circ} \mathrm{C}$.

Western blotting. For western blotting, total protein was extracted from cultured cells by lysis in RIPA buffer (Akron Biotechnology, Boca Raton, FL, USA) and protease inhibitor cocktail (Roche, Basel, Switzerland). The lysates were centrifuged at $20,000 \mathrm{xg}$ for $5 \mathrm{~min}$ at $4^{\circ} \mathrm{C}$. The protein concentration was measured using a standard BCA assay (Bio-Rad Laboratories, Hercules, CA, USA). Proteins $(40 \mu \mathrm{g})$ were disassociated by $10 \%$ sodium dodecyl sulfate-polyacrylamide gel electrophoresis (SDS-PAGE) using 5\% stacking gel and gradient separating gel with $6,8,10$ and $13 \%$, then blotted onto nitrocellulose membranes (Bio-Rad Laboratories). Membranes were blocked for $1 \mathrm{~h}$ in blocking solution and incubated with primary antibody overnight at $4^{\circ} \mathrm{C}$. The primary antibodies used were against E-cadherin 1:1,000; $\mathrm{N}$-cadherin 1:1,000;
PLAGL2 1:500; vimentin 1:500; $\beta$-catenin 1:1,000. All antibodies were purchased from Abcam (Cambridge, UK). Membranes were washed six times in Tris-buffered saline containing $0.1 \%$ Tween-20 (TBST) for $5 \mathrm{~min}$ and incubated with secondary antibodies, horseradish peroxidase anti-rabbit (1:5,000; Invitrogen) for $1 \mathrm{~h}$ at room temperature. After washing six times in TBST for $5 \mathrm{~min}$, the protein bands were visualized using electro-generated chemiluminescent (ECL) reagents (EMD Millipore). The optical density of bands was analyzed by reflectance densitometry on a Gel-Pro Analyzer (Media Cybernetics, Inc., Rockville, MD, USA).

The analysis of tumor cell metastasis on the lungs. Lung are the most common organ for colorectal cancer metastasis. Intra-vital video microscopy (IVVM) can directly observe the situation of tumor metastasis. In this study, the SW480 cells expressing recombinant green fluorescent protein were injected into rats and then the colonization and growth of colorectal cancer cells in lung tissue were observed and analyzed using the IVVM technique.

The tumor cell staining was performed in accordance with the manual of CellTracker ${ }^{\mathrm{TM}}$ Green CMFDA (Molecular Probes, Eugene, OR, USA) and the protocol was outlined below: Prepared $1 \mathrm{mM}$ CMFDA working solution was stored in the dark. For the SW480 cells with good growth state, the culture medium was drained and washed 3 times with PBS. CMFDA working solution $(10 \mu \mathrm{l})$ was added as well as culture media $2 \mathrm{ml}$ and incubated at $37^{\circ} \mathrm{C}, 5 \% \mathrm{CO}_{2}$ for 30-45 min. After washed 3 times with PBS, the cells were digested with $0.25 \%$ trypsin-EDTA and cell suspension was prepared. The cells were counted using a hemocytometer and the cell viability was determined with the trypan blue exclusion method (living cells in $>95 \%$ could be applied to the next step of the experiment).

Ninety healthy Wistar rats, 4-5 weeks old, weighing $\sim 110-130 \mathrm{~g}$, were purchased from the China Medical University Experimental Animal Center and were divided into 5 groups, each group of 18, using random number table method. All the experiments on animals were performed follow internationally recognized guidelines on animal welfare and the national regulations. The experimental protocol was conducted in accordance with the Ethical Guidelines for Investigations in Laboratory Animals and was approved by the Ethics Review Committee for Animal Experimentation of China Medical University (Shenyang, China). CMFDA-labeled SW480 cells were injected into the tail vein of the rats, $1 \times 10^{6}$ cells/ rat and 6 animals of each group were sacrificed at $2 \mathrm{~h}$, days 3 and 8 , respectively, and the lungs were excised. After ventilated perfusion, intact rat lung tissue was placed under a fluorescence microscope (glass plate $0.12 \mathrm{~mm}$ thick as slide) immediately and the number of metastatic cells or the fluorescence intensity on the surface of the pulmonary pleura was observed. The images were recorded with CCD camera Sony ICX205, CoolSNAP cf ${ }^{\mathrm{TM}}$ (Sony Corp., Tokyo, Japan) and analyzed using software of application of image analysis and processing, MetaMorph (Beijing Pioneer Technology, Beijing, China). When the cell number was counted, 50 view fields were selected under the visual field of 10 (ocular) x 10 (objective) magnifications. The actual number of tumor cells on $1-\mathrm{cm}^{2}$ pulmonary pleura was estimated by the following 
A

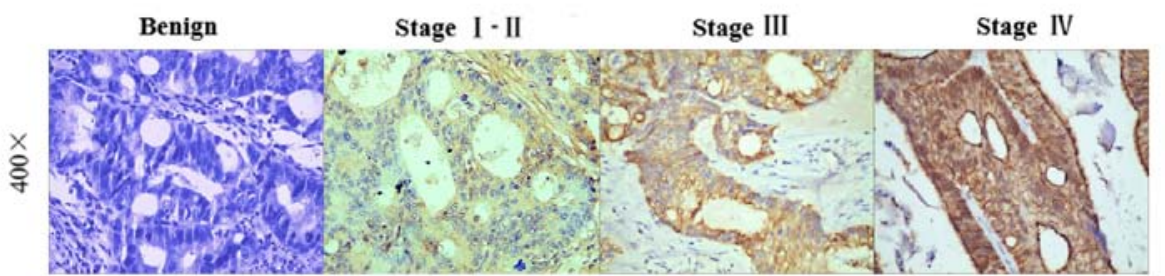

B

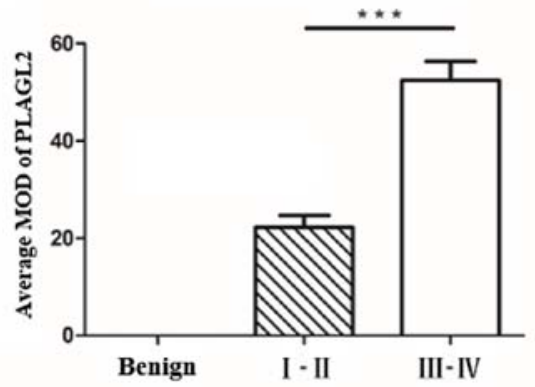

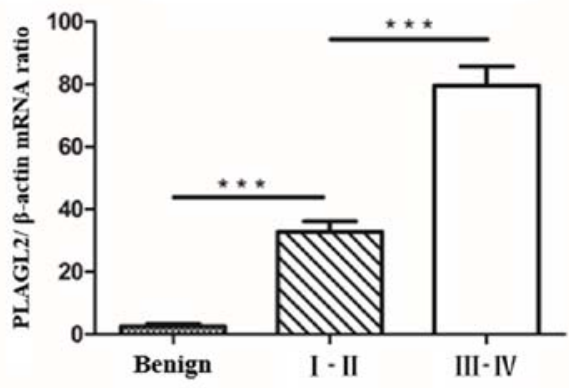

Figure 1. PLAGL2 protein and mRNA expression in CRC patients with different clinical stages and the control tissues. (A) IHC images of PLAGL2 expression in benign ( $n=44)$, malignant stage I-II $(n=14)$ and malignant stage III-IV $(n=30)$, respectively. (B) Statistical analyses of the average MOD for PLAGL2 staining in different tissues. (C) PLAGL2 mRNA were analyzed by real-time RT-PCR and expressed as PLAGL2/ $\beta$-actin mRNA ratio. $\left({ }^{* * * *} \mathrm{P}<0.001\right)$.

formula: The average cell number per view field/32.5 (each view field area is $0.325 \mathrm{~mm}^{2}$ ).

Statistical analysis. The SPSS version 20 statistical software package was used to optimize the image quality analysis. The $\chi^{2}$ test was used to assess the correlation between the PLAGL2 protein expression and various clinicopathological parameters. The enumeration data values are presented as mean \pm standard deviation (SD) and analyzed by one-way ANOVA. P<0.05 was considered statistically significant.

\section{Results}

PLAGL2 differential expression in CRCs and control benign tissues. In general, the PLAGL2 immunohistochemistry staining intensity gradually increased from benign, early stage to advanced stage (Fig. 1A). To further identify the differential expression of PLAGL2 between CRCs and their corresponding adjacent benign colorectal tissues, immunohistochemistry analysis and quantitative real-time RT-PCR (qRT-PCR) were performed in primary $\mathrm{CRC}$ and corresponding adjacent colorectal tissue samples from 44 patients. As shown in Fig. 1B and $\mathrm{C}$, both immunohistochemistry and qRT-PCR detection found that PLAGL2 expression in primary CRC tissues was significantly higher than that observed in adjacent non-tumor tissues $(\mathrm{P}<0.001)$; in addition, compared with the 14 cases in clinical stage I-II, the PLAGL2 expression was significantly higher in the samples in clinical stage III-IV $(\mathrm{P}<0.001)$. These results suggested that upregulation of PLAGL2 was correlated with the benign tissue canceration.

PLAGL2 upregulation is correlated with the clinicopathological parameters of CRC. The PLAGL2 expression level is represented with immunohistochemistry staining index evaluated by multiplying the staining intensity score to the positive cell score. Based on a measure of heterogeneity, a staining
Table I. Correlation between the PLAGL2 expression and the clinicopathological characteristics of CRC.

\begin{tabular}{|c|c|c|c|c|}
\hline \multirow[b]{2}{*}{ Characteristics } & \multicolumn{3}{|c|}{ PLAGL2 expression } & \multirow{2}{*}{$\frac{\chi^{2} \text { test }}{\text { P-value }}$} \\
\hline & $\begin{array}{c}\text { Total } \\
\text { cases }\end{array}$ & $\begin{array}{l}\text { Low } \\
(1-2)\end{array}$ & $\begin{array}{c}\text { High } \\
(3+)\end{array}$ & \\
\hline Age (years) & & & & 0.548 \\
\hline$\geq 55$ & 26 & 11 & 15 & \\
\hline$<55$ & 18 & 6 & 12 & \\
\hline Tumor size $(\mathrm{cm})$ & & & & 0.006 \\
\hline$\geq 3$ & 31 & 6 & 25 & \\
\hline$<3$ & 13 & 8 & 5 & \\
\hline Metastasis & & & & $<0.001$ \\
\hline With & 30 & 3 & 27 & \\
\hline Without & 14 & 9 & 5 & \\
\hline Clinical stage & & & & 0.034 \\
\hline I-II & 14 & 8 & 6 & \\
\hline III-IV & 30 & 6 & 24 & \\
\hline Pathological type & & & & 0.887 \\
\hline Adenocarcinoma & 27 & 8 & 19 & \\
\hline Mucinous & 12 & 3 & 9 & \\
\hline Undifferentiated & 5 & 1 & 4 & \\
\hline
\end{tabular}

index of 3 or greater was defined as high expression, and 2 or lower as low expression. In the univariate statistical analysis, the results in Table I show that the PLAGL2 expression level was correlated with tumor size $(\mathrm{P}=0.006)$, metastasis status $(\mathrm{P}<0.001)$ and clinical stage $(\mathrm{P}=0.034)$; while, there was no association with the patient's age or the tumor pathological subtype. These data indicated that the upregulation of PLAGL2 

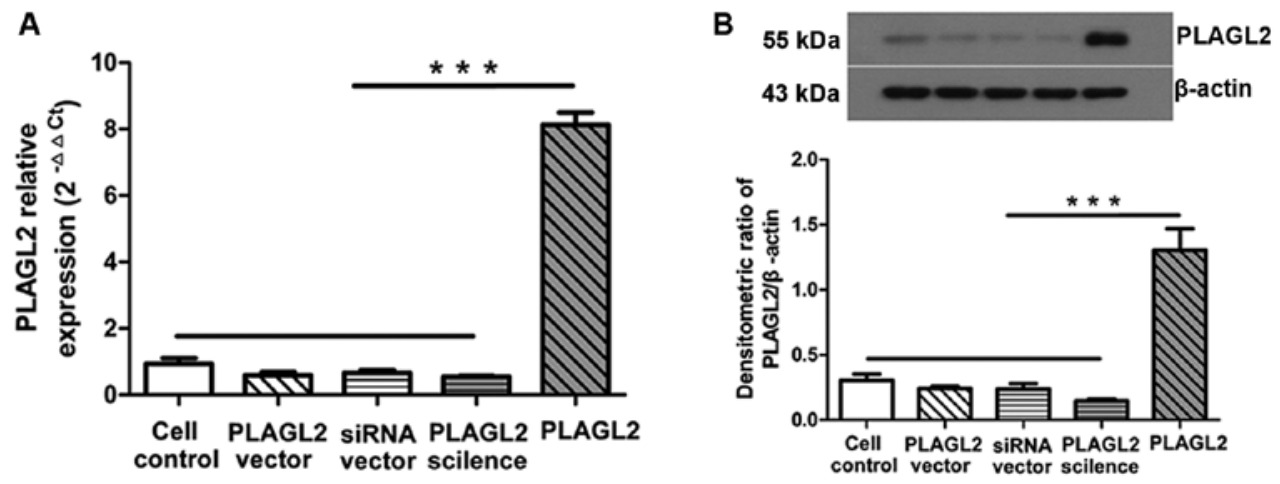

Figure 2. Transcription and expression of recombinant PLAGL2 in SW480 cells. (A) The in vitro transcription of PLAGL2 gene in the SW480 cells was analyzed by RT-PCR. (B) PLAGL2 protein expression was analyzed by western blot analysis. ${ }^{* * * *} \mathrm{P}<0.001$.

A
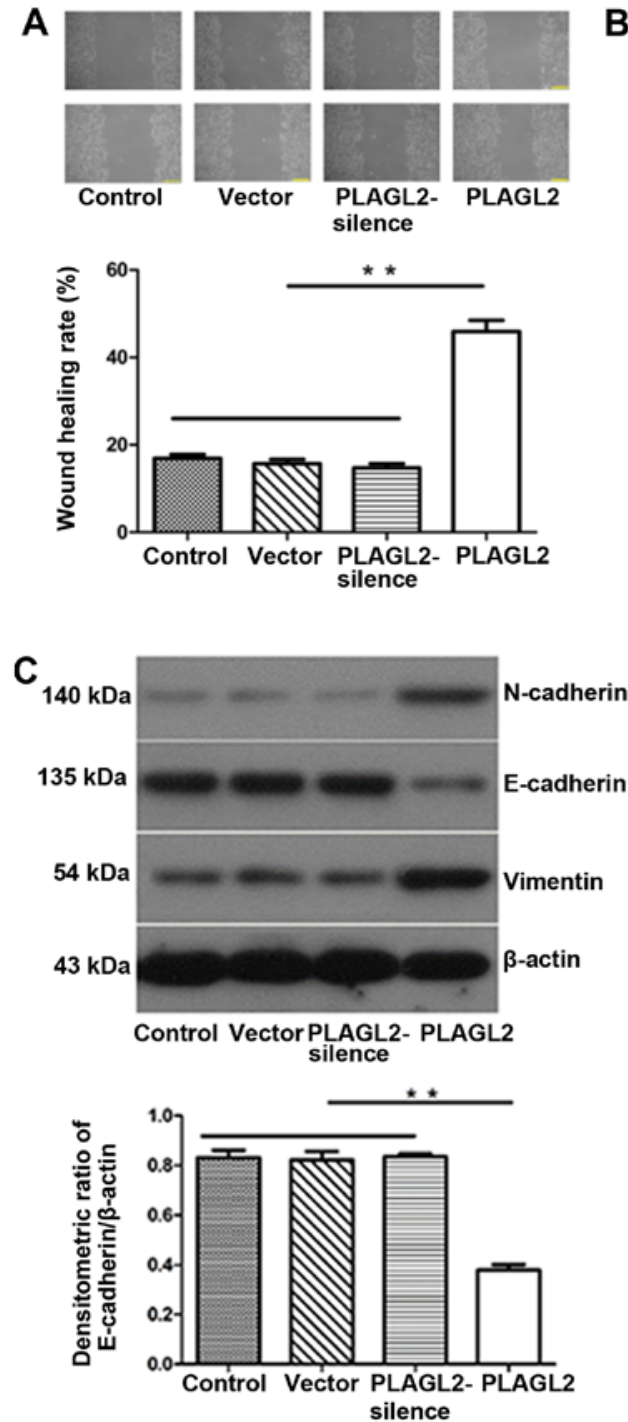

B
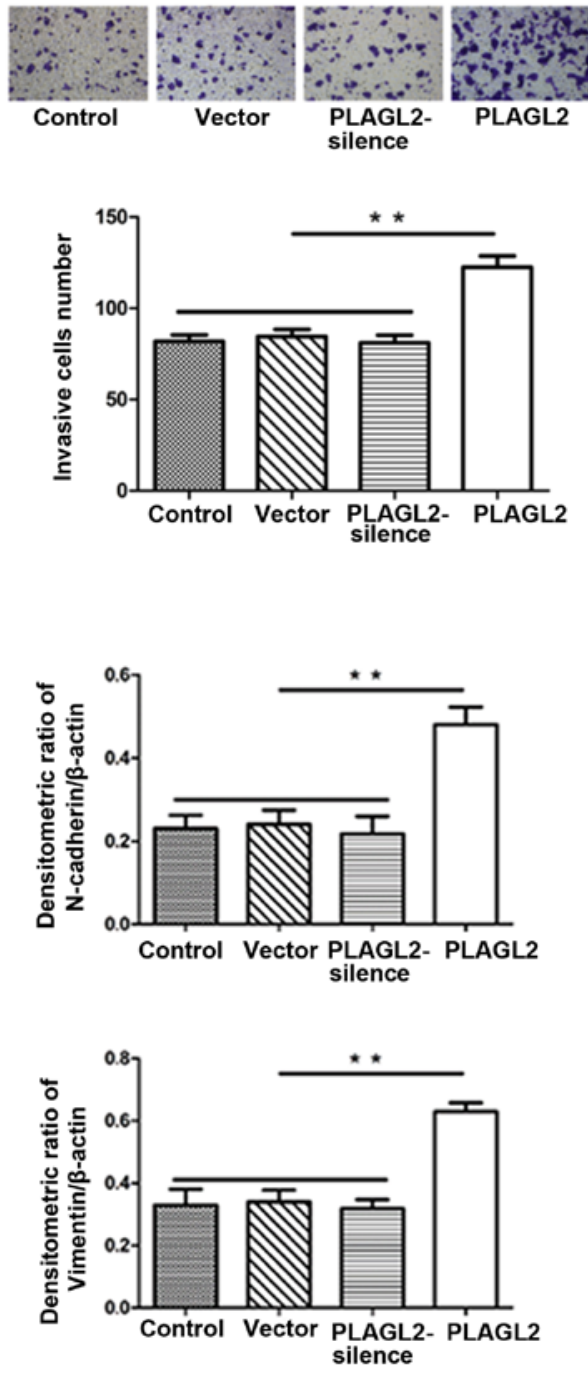

Figure 3. PLAGL2 mediated promotion of migration and invasion. (A) SW480 cell line, SW480 transfected pcDNA3.1 vector, SW480 transfected PLAGL2siRNA and SW480 transfected recombinant pcDNA3.1-PLAGL2 were cultured in 1\% FBS medium. Migration assay was performed as described in Materials and methods, and the microscopic analysis was assessed at the time of the scratch $(0 \mathrm{~h})$ and after $24 \mathrm{~h}(24 \mathrm{~h})$. The values are expressed as wound healing rate (width $0 \mathrm{~h}$ - width $12 \mathrm{~h} /$ width $0 \mathrm{~h} \times 100 \%$ ). (B) The cell number of invasion was compared between different groups. (C) Whole SW480 cell lysates were immunoblotted for E-cadherin, vimentin or N-cadherin. All membranes were re-probed with anti- $\beta$-actin antibody to confirm equal loading. Data are presented as mean \pm SD of six independent experiments. ${ }^{* *} \mathrm{P}<0.01$.

expression predicated advanced clinicopathological features and poor prognosis in patients with CRC.
Construction of high expression or low expression of PLAGL2 in SW480 cell lines. To confirm the role of PLAGL2 in 

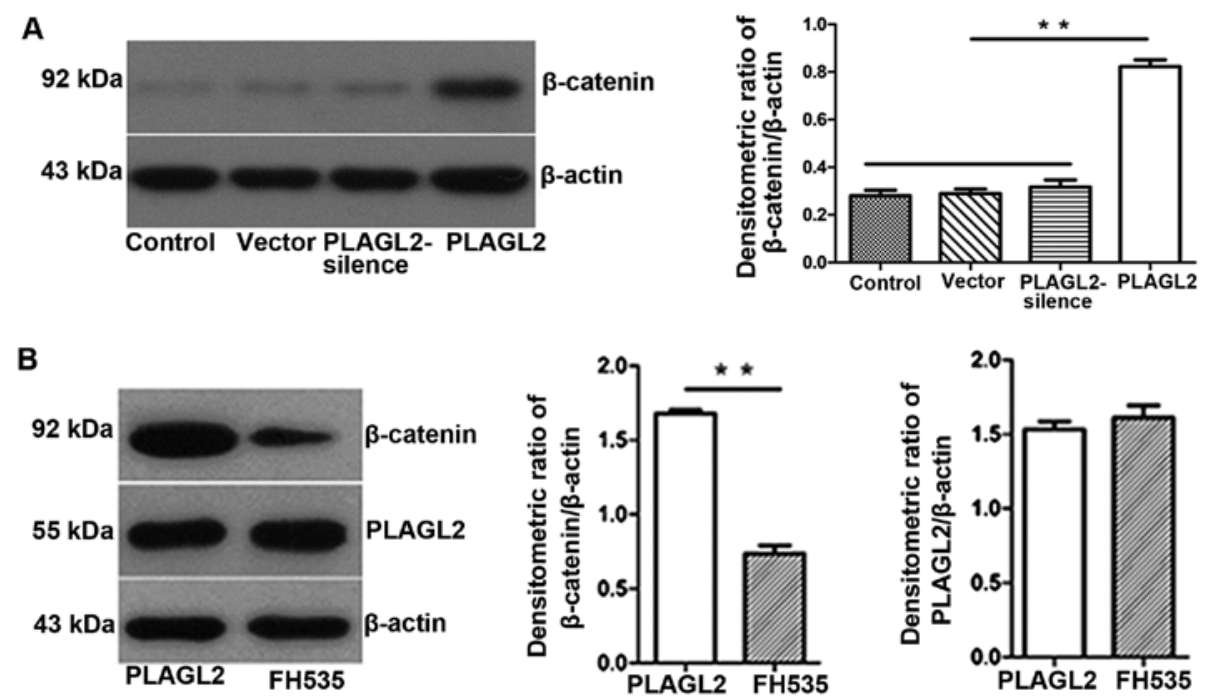

C
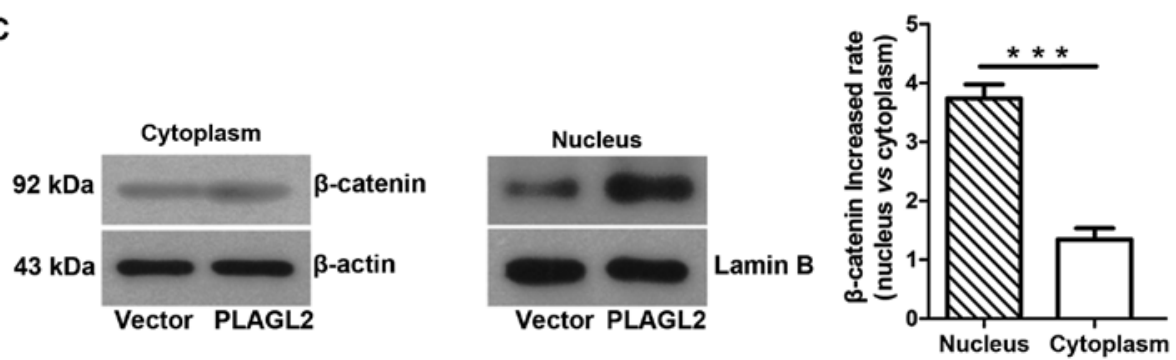

Figure 4. The role of PLA GL2 on regulation of $\beta$-catenin expression. (A) Western blot results validating the $\beta$-catenin expression significantly influenced by PLAGL2. (B) The PLAGL2 group represented the PLAGL2 transfected SW480 cells; the FH535 is the Wnt/ $\beta$-catenin inhibitor co-cultured with PLAGL2 transfected SW480 cells for 48 h. (C) Cytoplasmic and nuclear levels of $\beta$-catenin in SW480 cell high-expressed PLAGL2 or not. Lamin B1 used as a sample loading control. ${ }^{* *} \mathrm{P}<0.01 ;{ }^{* * *} \mathrm{P}<0.001$.

promoting tumorigenesis and metastasis of colorectal cells and to the mechanisms, the full-length coding sequence (CDS) encoding PLAGL2 was cloned into pcDNA3.1 and the recombinant plasmid pcDNA3.1-PLAGL2 was digested with $B a m \mathrm{HI}+E c o$ RI. At the same time, siRNA for PLAGL2 was designed and synthesized by Guangzhou Ribobio, Co., Ltd., (Guangzhou, China) and the effect of siRNA was identified by qRT-PCR. The in vitro transcription of PLAGL2 gene and PLAGL2 silencing in the SW480 cells were analyzed by real-time PCR and western blot analysis. The cycle number of PLAGL2 at which the amplification reached the threshold was normalized against $\beta$-actin cycle number to determine the relative copy numbers between SW480 cell line, pcDNA3.1 transfected SW480 cell line, PLAGL2 silenced cell line and pcDNA3.1-PLAGL2 transfected cell line. The PLAGL2 exhibited significantly higher level of transcription in the pcDNA3.1-PLAGL2 transfected cell line compared with PLAGL2 silencing cell line, pcDNA3.1 transfected cell line and SW480. The results suggested that PLAGL2 gene transcription was upregulated in pcDNA3.1-PLAGL2 transfected SW480 cell line (Fig. 2A). Expression of PLAGL2 protein in SW480 cells was detected by western blot analysis. The results confirmed that PLAGL2 protein was significantly highly expressed in the pcDNA3.1-PLAGL2 transfected SW480 cells, whereas, very weak expression was seen in other cells (Fig. 2B). The results showed that the colorectal cancer cell line stably overexpressing exogenous PLAGL2 and PLAGL2-silence were successfully established. Since the expression change of PLAGL2 in pcDNA3.1 vector and empty vector of PLAGL2 silence was similar, in the subsequent results, only one set of vectors was used to represent both vector controls.

The high expression of PLAGL2 significantly enhances the ability of invasion and metastasis and EMT marker expression of SW480 cell lines compared with low expression strain. Promotion effect of PLAGL2 on SW480 cell migration was evaluated by scratch wound healing assay (Fig. 3A). At time-point $0 \mathrm{~h}$, scraped cells were photographed. After $24 \mathrm{~h}$, migration of cells into wounded areas was effectively increased in the PLAGL2 group. This result suggests that PLAGL2 promoted migration of the SW480 cells. PLAGL2 promoting invasion of SW480 cell invasion was determined by Transwell invasion assay. PLAGL2 significantly promoted invasion of the cells (Fig. 3B). Quantitative data derived from three independent experiments supported that PLAGL2 high expression effectively prevented invasion characteristics of tumor cells. The expression level of EMT markers, $\mathrm{N}$-cadherin and vimentin and epithelial marker, E-cadherin, were compared between the PLAGL2 silenced SW480 cells and PLAGL2 transfected SW480 cells by western blot assay. The results of this analysis confirmed that the SW480 cells (low expressed PLAGL2) and PLAGL2 silenced cells produced $\mathrm{N}$-cadherin and vimentin in substantially lower amounts than the SW480 cells highly expressing PLAGL2 and with opposite E-cadherin changing in the cells (Fig. 3C). 

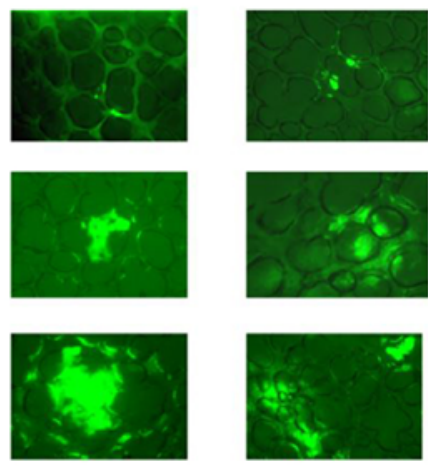

SW480
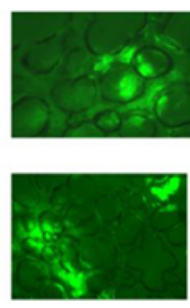

PLAGL2-silence
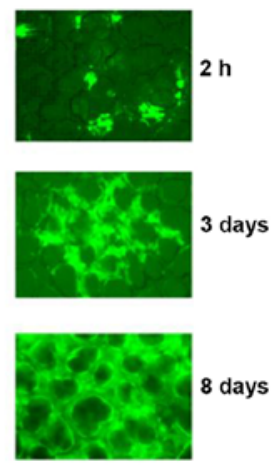

PLAGL2
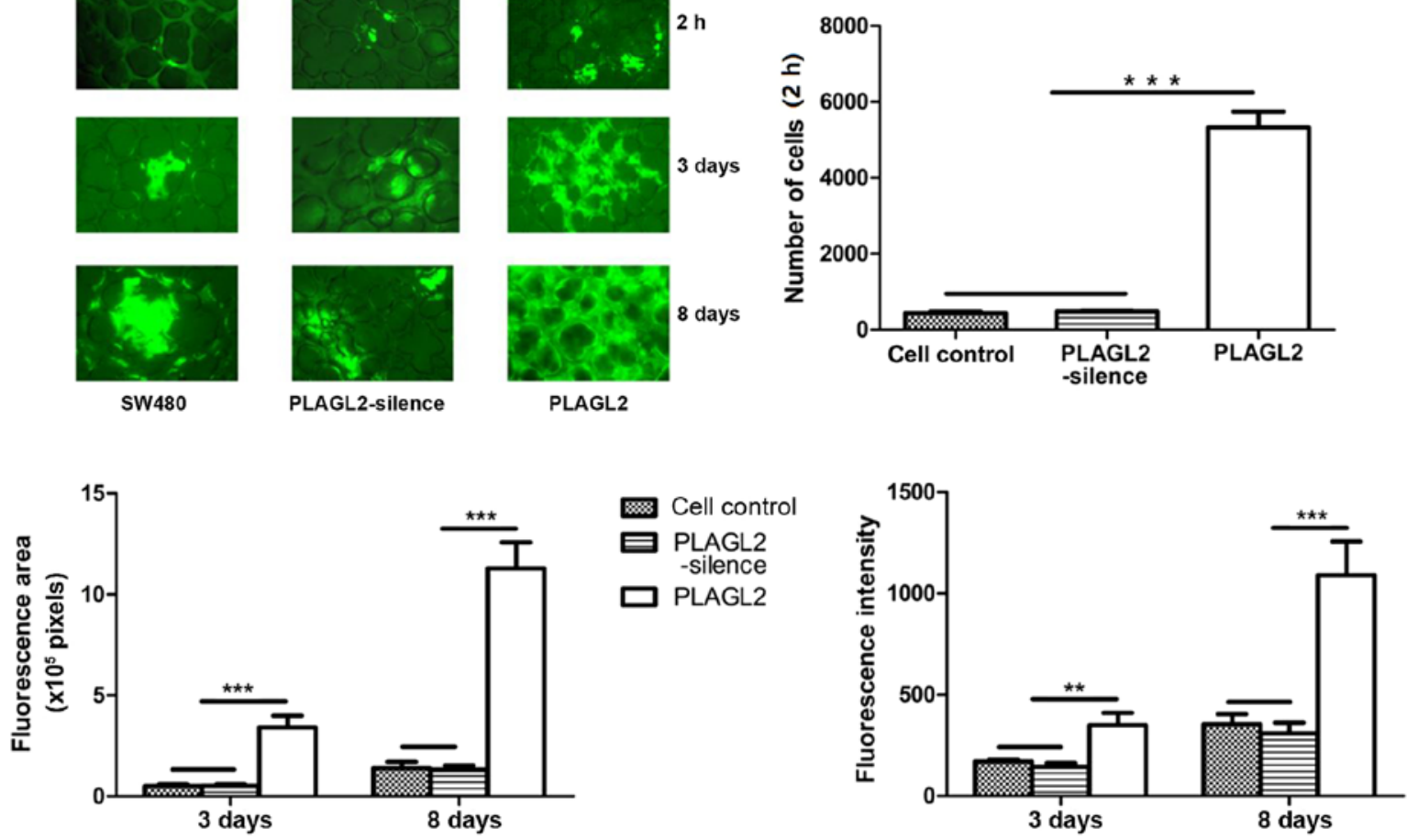

Figure 5. PLAGL2 overexpression in SW480 cells promotes tumor lung metastasis in rats. PLAGL2 overexpression caused increase of fluorescence intensity (left) and area (right) on the pulmonary pleura of the rats injected with SW480 cells, PLAGL2-silenced SW480 cells and PLAGL2 transfected SW480 cells, respectively (mean $\left.\pm \mathrm{SD}, \mathrm{n}=6,{ }^{* *} \mathrm{P}<0.01,{ }^{* * *} \mathrm{P}<0.001\right)$.

The results also revealed that the vectors had no effect on the protein expression.

The role of PLAGL2 on regulating $\beta$-catenin expression. Subsequently, to verify whether the PLAGL2 promoted CRC cell EMT through the wnt/ $\beta$-catenin signaling pathway, we analyzed the $\beta$-catenin protein levels of the cell lysates. The results showed that the whole protein level of $\beta$-catenin in the PLAGL2 cells were significant increased compared with the control cells, vectors transected cells and the PLAGL2silenced cells (Fig. 4A). Then, $20 \mathrm{mM}$ FH535, the $\beta$-catenin inhibitor, was used to co-incubate the PLAGL2 transfected SW480 cells for $48 \mathrm{~h}$. The $\beta$-catenin expression was activated after PLAGL2 decreased significantly, but PLAGL2 expression was not affected, after FH535 co-incubation. This suggested that PLAGL2 is an upstream protein inducing EMT through activating the $\beta$-catenin pathway (Fig. $4 \mathrm{~B}$ ). $\beta$-catenin is a nuclear transcription factor; therefore, we further used nuclei plasma separation technique to detect the regulation of nuclear $\beta$-catenin in colorectal cancer cell line PLAGL2. The results showed that the overexpression of PLAGL2 increased the expression of $\beta$-catenin in the nucleus significantly; while the cytoplasmic $\beta$-catenin increased but the change was not obvious. After overexpression of PLAGL2, the increase of $\beta$-catenin expression in the nucleus was $\sim 2-3$ times higher than that in the cytoplasm (Fig. 4C).

High expression of PLAGL2 promotes SW480 cell metastasis in vivo. In the course of tumor metastasis, the adhesion of metastatic tumor cells to vascular endothelium is one of the key steps in the transfer process. Lung is the most common organ for tumor metastasis occurrence of colorectal cancer. To determine whether downregulation of PLAGL2 is capable of suppressing metastasis in lung cancer, the PLAGL2 introduced SW480 cells, PLAGL2 silenced SW480 cells and SW480 cells were injected into rats and evaluated for metastatic colonization capacity in a tail-vein assay. Since the in vitro experiments showed that the empty vectors did not affect the expression of PLAGL2, in order to reduce the number of experimental animals as much as possible, the vector controls were not set, but only PLAGL2 high expression, PLAGL2 low expression and cell control group were set in the in vivo experiments.

The rats were dissected after $2 \mathrm{~h}$ of the cell injection into the caudal vein and the intact lung tissues were observed under fluorescence microscope. Retention of metastatic tumor cells in pulmonary capillaries could be seen and the knockdown of PLAGL2 genes led to significant suppression of metastatic cell number in the lungs. The reduction in the cell numbers had statistical significance (Fig. 5). Three days later, due to excessive colonization of the cells on the lung pleural surface forming cell clusters that could not be counted, the fluorescence intensity was applied for cell metastasis assessment. The rats were dissected on days 3 and 8 , respectively. The lung tissue was taken for observation and image acquisition. MetaMorph software was used to measure the area and the fluorescence intensity of each group. With the increase of the number of days, the total fluorescence area and the fluorescence intensity of the cell clusters formed on the lung surface was also significantly increased. The statistical comparison between PLAGLA group with cell control group and comparison between PLAGLA group with PLAGL2 silenced group were all significant $(\mathrm{P}<0.01)$ (Fig. 5). 


\section{Discussion}

PLAGL2 is a member of the polymorphic adenoma gene zinc finger protein family, the other members include PLAGl and PLAGLl. The PLAG family protein, mainly as a nuclear transcriptional regulator, is important to regulate various gene expressions, including physiological cell proliferation and pathological tumorigenesis. Some previous studies have demonstrated that PLAGL2 is a transcription factor that overexpress and has active function in cancer progression (41-43). In the present study, we started with an overview of 44 colorectal patients' data for analyzing the relationship between the PLAGL2 expression and the clinicopathological manifestation. Here, we report the overexpression of PLAGL2 at the invasive and high grade cases. Thus, the PLAGL2 genes may be a new severity hallmark of the CRC patients. In this context, we also confirmed the significant upregulation of PLAGL2 by immunohistochemistry in the tumor samples from clinical stage III-IV patients. PLAGL2 was stained in both cytoplasm and nuclei. Because of these finding, we initially confirmed the tumor metastasis promoting role of PLAGL2. It showed clear and consistent role on CRC cell proliferation, invasion, migration and evident through both pathological tests and the clinicopathological data retrospective analysis. We also found that the malignant level of CRC has a correlation in an PLAGL2 expression-dependent manner. Our results further validated and confirmed a previous study (40).

In the present study, PLAGL2 overexpression is necessary for EMT as demonstrated by the pcDNA3.1-PLAGL2 vector transfection and stable silencing via PLAGL2-silence vector transfection, respectively. The results indicated that PLAGL2 upregulation may facilitate CRC tumor cell invasion and metastasis by regulating multiple EMT molecular expression parallel or dependent, including $\beta$-catenin, E-cadherin, vimentin and $\mathrm{N}$-cadherin with in vitro $\mathrm{CRC}$ model and these promote the ability of tumor cell migration and invasion; in contrast, the SW480 cells with low expression of PLAGL2 showed more epithelial characteristics. Therefore, the current studies consistently suggest that PLAGL2 is a key protein and might have potential to effectively induce cell EMT by itself.

$W n t / \beta$-catenin activation was necessary for EMT, although it might not be required for the final effects. Previously it was reported that tumor cells undergo EMT in response to $W n t / \beta$-catenin activation and inhibition of the pathway could induce a reversal in the expression of epithelial to EMT markers with the restoration of the epithelial marker in carcinoma (44). The results of the present study showed that PLAGL2 upregulation modulates $\mathrm{Wnt} / \beta$-catenin activity in SW480 cells so that tumor cells may obtain the ability of migration and invasion by this pathway activity. Whether PLAGL2 is an indispensable molecule or just facilitate cell EMT is still unclear, its overexpression represents an important initiation step for tumor cells to gain a migration and/or invasion advantage. Intriguingly, when the PLAGL2 transfected SW480 cells were co-cultured with $W n t / \beta$-catenin inhibitor FH535, the $\beta$-catenin protein expression was significantly prohibited but the PLAGL2 expression maintaining the normal. Therefore, it can be postulated that PLAGL2 overexpression was necessary and initiation for induction of tumor cell EMT progression and PLAGL2 acts as the upstream molecule in $W n t / \beta$-catenin signaling pathway in favor of EMT rather than directly acting EMT itself. This observation indicated that PLAGL2 may be an essential bio-factor in tumor cell migration and invasion that is upregulated in CRC, and its depletion might be accompanied by profound inhibition of EMT and thus could be a novel therapeutic target in metastatic carcinoma. We further defined the relationships of $\beta$-catenin in nucleus and plasma using nucleus plasma isolation techniques. It can be seen that with the overexpression of the PLAGl2, the expression level of $\beta$-catenin in the nucleus increased and the change in plasma was not obvious. These results clearly told us that PLAGL2 mainly regulates the expression of $\beta$-catenin in the nucleus.

Finally, to confirm that PLAGL2 acts as a tumor EMT promoter during colorectal cancer lung metastasis in vivo. The intra-vital video microscopy (IVVM) technique was used to show an early and constant enhanced tumor metastasis and growth progression. PLAGL2 overexpressing SW480 cell injection into rats led to an increase of tumor colony formation on the pulmonary pleura in both very early and late stage, compared with the SW480 cell control group and the PLAGL2 silenced group.

In conclusion, the present study characterized PLAGL2 as a key regulator of EMT in SW480 cells, because increased migration and invasion activities of SW480 cells observed with PLAGL2 transfection. Additionally, the findings of this study also indicate that EMT activity contributed to the overexpression of PLAGL2 molecule influencing several EMT relative protein expression alteration. These data suggested that, $W n t / \beta$-catenin pathway may be involved in the EMT and PLAGL2 might contribute substantially to the basic role of procession. However, the accurate mechanism of PLAGL2 function on $W n t / \beta$-catenin will have to be addressed in our follow-up study.

\section{Acknowledgements}

The present study was supported by the Natural Science Foundation of Liaoning Province (no. 2016024477) from the Science and Technology Department of Liaoning Province.

\section{References}

1. Siegel R, Naishadham D and Jemal A: Cancer statistics, 2013. CA Cancer J Clin 63: 11-30, 2013.

2. Siegel R, Desantis C and Jemal A: Colorectal cancer statistics, 2014. CA Cancer J Clin 64: 104-117, 2014.

3. Siegel R, Ward E, Brawley O and Jemal A: Cancer statistics, 2011: The impact of eliminating socioeconomic and racial disparities on premature cancer deaths. CA Cancer J Clin 61: 212-236, 2011.

4. Krawczyk N, Meier-Stiegen F, Banys M, Neubauer H, Ruckhaeberle E and Fehm T: Expression of stem cell and epithelial-mesenchymal transition markers in circulating tumor cells of breast cancer patients. BioMed Res Int 2014: 415721, 2014.

5. Chen C, Zimmermann M, Tinhofer I, Kaufmann AM and Albers AE: Epithelial-to-mesenchymal transition and cancer stem(-like) cells in head and neck squamous cell carcinoma. Cancer Lett 338: 47-56, 2013.

6. Lamouille S, Xu J and Derynck R: Molecular mechanisms of epithelial-mesenchymal transition. Nat Rev Mol Cell Biol 15: 178-196, 2014.

7. Kalluri R and Weinberg RA: The basics of epithelial-mesenchymal transition. J Clin Invest 119: 1420-1428, 2009. 
8. De Craene B and Berx G: Regulatory networks defining EMT during cancer initiation and progression. Nat Rev Cancer 13: 97-110, 2013.

9. Loboda A, Nebozhyn MV, Watters JW, Buser CA, Shaw PM, Huang PS, Van't Veer L, Tollenaar RA, Jackson DB, Agrawal D, et al: EMT is the dominant program in human colon cancer. BMC Med Genomics 4: 9, 2011.

10. Bates RC, Goldsmith JD, Bachelder RE, Brown C, Shibuya M, Oettgen P and Mercurio AM: Flt-1-dependent survival characterizes the epithelial-mesenchymal transition of colonic organoids. Curr Biol 13: 1721-1727, 2003

11. Iwai S, Yonekawa A, Harada C, Hamada M, Katagiri W, Nakazawa M and Yura Y: Involvement of the Wnt- $\beta$-catenin pathway in invasion and migration of oral squamous carcinoma cells. Int J Oncol 37: 1095-1103, 2010

12. Hu TH, Yao Y, Yu S, Han LL, Wang WJ, Guo H, Tian T, Ruan ZP, Kang XM, Wang J, et al: SDF-1/CXCR4 promotes epithelialmesenchymal transition and progression of colorectal cancer by activation of the $\mathrm{Wnt} / \beta$-catenin signaling pathway. Cancer Lett 354: 417-426, 2014.

13. He W, He S, Wang Z, Shen H, Fang W, Zhang Y, Qian W, Lin M, Yuan J, Wang J, et al: Astrocyte elevated gene-1 (AEG-1) induces epithelial-mesenchymal transition in lung cancer through activating Wnt/ $\beta$-catenin signaling. BMC Cancer 15: 107, 2015.

14. Tsuchiya R, Yamamoto $G$, Nagoshi $Y$, Aida $T$, Irie $T$ and Tachikawa T: Expression of adenomatous polyposis coli (APC) in tumorigenesis of human oral squamous cell carcinoma. Ora Oncol 40: 932-940, 2004

15. Sabbah M, Emami S, Redeuilh G, Julien S, Prévost G, Zimber A, Ouelaa R, Bracke M, De Wever O and Gespach C: Molecular signature and therapeutic perspective of the epithelial-to-mesenchymal transitions in epithelial cancers. Drug Resist Updat 11: $123-151,2008$

16. Gilles C, Polette M, Mestdagt M, Nawrocki-Raby B, Ruggeri P, Birembaut $\mathrm{P}$ and Foidart JM: Transactivation of vimentin by beta-catenin in human breast cancer cells. Cancer Res 63 2658-2664, 2003.

17. Guo M, Ehrlicher AJ, Mahammad S, Fabich H, Jensen MH, Moore JR, Fredberg JJ, Goldman RD and Weitz DA: The role of vimentin intermediate filaments in cortical and cytoplasmic mechanics. Biophys J 105: 1562-1568, 2013.

18. Pan Y, Li X, Duan J, Yuan L, Fan S, Fan J, Xiaokaiti Y, Yang H, Wang Y and Li X: Enoxaparin sensitizes human non-small-cell lung carcinomas to gefitinib by inhibiting DOCK1 expression, vimentin phosphorylation, and Akt activation. Mol Pharmacol 87: 378-390, 2015

19. Satelli A, Brownlee Z, Mitra A, Meng QH and Li S: Circulating tumor cell enumeration with a combination of epithelial cell adhesion molecule- and cell-surface vimentin-based methods for monitoring breast cancer therapeutic response. Clin Chem 61 259-266, 2015

20. Calangiu CM, Simionescu CE, Stepan AE, Cernea D, Zăvoi RE and Mărgăritescu C: The expression of CK19, vimentin and E-cadherin in differentiated thyroid carcinomas. Rom J Morphol Embryol 55: 919-925, 2014

21. Shirahata A, Sakata M, Sakuraba K, Goto T, Mizukami H, Saito M, Ishibashi K, Kigawa G, Nemoto H, Sanada Y, et al: Vimentin methylation as a marker for advanced colorectal carcinoma. Anticancer Res 29: 279-281, 2009.

22. Kang Y and Massagué J: Epithelial-mesenchymal transitions: Twist in development and metastasis. Cell 118: 277-279, 2004.

23. Natalwala A, Spychal R and Tselepis C: Epithelial-mesenchymal transition mediated tumourigenesis in the gastrointestinal tract. World J Gastroenterol 14: 3792-3797, 2008.

24. Marsit CJ, Posner MR, McClean MD and Kelsey KT: Hypermethylation of E-cadherin is an independent predictor of improved survival in head and neck squamous cell carcinoma. Cancer 113: 1566-1571, 2008.

25. Pannone G, Santoro A, Feola A, Bufo P, Papagerakis P, Lo Muzio L, Staibano S, Ionna F, Longo F, Franco R, et al: The role of E-cadherin down-regulation in oral cancer: CDH1 gene expression and epigenetic blockage. Curr Cancer Drug Targets 14: 115-127, 2014.

26. Cekanova M, Fernando RI, Siriwardhana N, Sukhthankar M, De la Parra C, Woraratphoka J, Malone C, Ström A, Baek SJ, Wade PA, et al: BCL-2 family protein, BAD is down-regulated in breast cancer and inhibits cell invasion. Exp Cell Res 331: 1-10, 2015.
27. Cui T, Srivastava AK, Han C, Yang L, Zhao R, Zou N, Qu M, Duan W, Zhang X and Wang QE: XPC inhibits NSCLC cell proliferation and migration by enhancing $\mathrm{E}$-Cadherin expression. Oncotarget 6: 10060-10072, 2015.

28. Hazan RB, Phillips GR, Qiao RF, Norton L and Aaronson SA Exogenous expression of $\mathrm{N}$-cadherin in breast cancer cells induces cell migration, invasion, and metastasis. J Cell Biol 148 779-790, 2000.

29. Kim JB, Islam S, Kim YJ, Prudoff RS, Sass KM, Wheelock MJ and Johnson KR: N-Cadherin extracellular repeat 4 mediates epithelial to mesenchymal transition and increased motility. J Cell Biol 151: 1193-1206, 2000.

30. Qi J, Chen N, Wang J and Siu CH: Transendothelial migration of melanoma cells involves $\mathrm{N}$-cadherin-mediated adhesion and activation of the beta-catenin signaling pathway. Mol Biol Cell 16: 4386-4397, 2005.

31. Vergara D, Simeone P, Latorre D, Cascione F, Leporatti S, Trerotola M, Giudetti AM, Capobianco L, Lunetti P, Rizzello A, et al: Proteomics analysis of E-cadherin knockdown in epithelial breast cancer cells. J Biotechnol 202: 3-11, 2015.

32. Florian S, Sonneck K, Czerny M, Hennersdorf F, Hauswirth AW, Bühring HJ and Valent P: Detection of novel leukocyte differentiation antigens on basophils and mast cells by HLDA8 antibodies. Allergy 61: 1054-1062, 2006.

33. Tan EJ, Kahata K, Idås O, Thuault S, Heldin CH and Moustakas A: The high mobility group A2 protein epigenetically silences the Cdh1 gene during epithelial-to-mesenchymal transition. Nucleic Acids Res 43: 162-178, 2015.

34. Furukawa T, Adachi Y, Fujisawa J, Kambe T, Yamaguchi-Iwai Y, Sasaki R, Kuwahara J, Ikehara S, Tokunaga R and Taketani S: Involvement of PLAGL2 in activation of iron deficientand hypoxia-induced gene expression in mouse cell lines. Oncogene 20: 4718-4727, 2001.

35. Landrette SF, Kuo YH, Hensen K, Barjesteh van Waalwijk van Doorn-Khosrovani S, Perrat PN, Van de Ven WJ, Delwel R and Castilla LH: Plag1 and Plagl2 are oncogenes that induce acute myeloid leukemia in cooperation with Cbfb-MYH11. Blood 105: 2900-2907, 2005.

36. Yang YS, Yang MC and Weissler JC: Pleiomorphic adenoma gene-like 2 expression is associated with the development of lung adenocarcinoma and emphysema. Lung Cancer 74: 12-24, 2011.

37. Zheng H, Ying H, Wiedemeyer R, Yan H, Quayle SN, Ivanova EV, Paik JH, Zhang H, Xiao Y, Perry SR, et al: PLAGL2 regulates Wnt signaling to impede differentiation in neural stem cells and gliomas. Cancer Cell 17: 497-509, 2010

38. Sekiya R, Maeda M, Yuan H, Asano E, Hyodo T, Hasegawa H, Ito S, Shibata K, Hamaguchi M, Kikkawa F, et al: PLAGL2 regulates actin cytoskeletal architecture and cell migration. Carcinogenesis 35: 1993-2001, 2014.

39. Gadea G, de Toledo M, Anguille C and Roux P: Loss of p53 promotes RhoA-ROCK-dependent cell migration and invasion in 3D matrices. J Cell Biol 178: 23-30, 2007.

40. Liu B, Lu C, Song YX, Gao P, Sun JX, Chen XW, Wang MX, Dong YL, Xu HM and Wang ZN: The role of pleomorphic adenoma gene-like 2 in gastrointestinal cancer development, progression, and prognosis. Int J Clin Exp Pathol 7: 3089-3100, 2014.

41. Kas K, Voz ML, Röijer E, Aström AK, Meyen E, Stenman G and Van de Ven WJ: Promoter swapping between the genes for a novel zinc finger protein and beta-catenin in pleiomorphic adenomas with $\mathrm{t}(3 ; 8)(\mathrm{p} 21 ; \mathrm{q} 12)$ translocations. Nat Genet 15 170-174, 1997.

42. Van Dyck F, Delvaux EL, Van de Ven WJ and Chavez MV: Repression of the transactivating capacity of the oncoprotein PLAG1 by SUMOylation. J Biol Chem 279: 36121-36131, 2004.

43. Lanzara C, Ficarella R, Totaro A, Chen X, Roberto R, Perrotta S, Lasalandra C, Gasparini P, Iolascon A and Carella M: Congenital dyserythropoietic anemia type II: Exclusion of seven candidate genes. Blood Cells Mol Dis 30: 22-29, 2003.

44. Warrier S, Bhuvanalakshmi G, Arfuso F, Rajan G, Millward M and Dharmarajan A: Cancer stem-like cells from head and neck cancers are chemosensitized by the Wnt antagonist, sFRP4, by inducing apoptosis, decreasing stemness, drug resistance and epithelial to mesenchymal transition. Cancer Gene Ther 21: 381-388, 2014. 